\title{
Investing in nutrition at the national level: an African perspective
}

\author{
B Y FESTO P. KAVISHE \\ UNICEF, ESARO, PO Box 44145, Nairobi, Kenya
}

\begin{abstract}
Investment of any type requires an enabling environment which gives confidence to the investor. Investing in nutrition is no exception. It requires conducive political, economic, technological and social environments. These dynamic environments are not determined only by economic considerations but by moral and ethical considerations as well. Thus, while investing in nutrition will certainly give economic returns, it should also be considered as a human right (Jonsson, 1993a). The present paper aims to provide an African perspective at national level, using Tanzania as an example, on ways in which the impact and quality of various interventions can be maximized through increasing investments in nutrition.
\end{abstract}

\section{AFRICA'S FLUID DEVELOPMENT}

Contrary to much conventional thinking, in spite of deep distortions in production and trade structures inherited by most African countries at independence, the economy of Africa performed relatively well during the 1960 s and 1970 s, with gross domestic product and exports growing more rapidly than those in South Asia and with a massive expansion in education and health care across the continent (World Bank, 1989, 1993a, $b$; UNICEF, 1992, 1993). However, the last decade has been dubbed 'the lost decade' for Africa because of a downward spiral of economic and social decline. Africa now remains the only continent with famine and massive hunger and the only continent where nutrition is deteriorating (United Nations Administration and Coordination Committee/ Subcommittee on Nutrition, 1993). In addition, the present deepening political crises in several countries of the region, including Angola, Rwanda and Somalia, illustrate the ease with which social, economic and political crises can reverse decades of progress. Africa's dilemma should be judged from a historical perspective and not merely the present context. Africa more than any other continent bore the brunt of the effects of the slave trade, the colonial scrambles and the games of the cold war, including its end. In addition most of Africa's development policies have been shaped not by endogenous evolution but mainly by external forces of divergent interests. Historical treatises like Dumont's (1962) False Start in Africa and Davidson's (1992) The Black Man's Burden provide deep analytical historical contexts. Thus, Africa's nutrition problems are, in great part, a reflection of this historical process.

\section{EMERGING HOPES}

Against this pessimistic picture painted by our media in moving horror scenes of starvation, massacres, pestilence and unimaginable destruction, are growing hopes of progress on a larger scale which rarely find their way to the world media. After nearly three and a half centuries, apartheid has eventually been dismantled. A wave of democratization and decentralization is sweeping through Africa, and several countries 
are reversing the trend of social and economic decline. In addition there is some progress in the resolution of some conflicts, as in Mozambique, made possible by the end of apartheid and the cold war. Uganda, with a history of 15 years of dictatorship and destruction by civil war, provides the best example of how subsequent good governance can restore peace and social and economic development.

There are also important developments for improvement of nutrition. Even in the face of severe economic conditions some countries in Africa have been able to achieve improvements in nutrition significantly better than expected, given their level of poverty. Among the twelve top countries listed by the United Nations International Children's Emergency Fund (UNICEF) in the Progress of Nations (UNICEF, 1994) where child nutrition is significantly better than expected for their gross national product (GNP) per capita, half are in Africa, the top two being Uganda and Tanzania which have national positive performance gaps of 15 and 14 respectively. Tanzania and Zimbabwe are also listed as the only African countries where more than $10 \%$ of children are malnourished, but where trends indicate that they are on target to achieve the mid-decade goal for nutrition (UNICEF, 1994). Moreover, Tanzania is the only African country with comprehensive programmes for the control of the major three micronutrient deficiencies of Fe, I and vitamin A. This shows that much improvement in health and nutrition can be achieved now without waiting for the trickle down effects of economic development, provided development programmes adopt effective practices.

\section{TANZANIA'S EXPERIENCE IN INVESTING IN NUTRITION}

The experience depicted in the present paper refers mainly to mainland Tanzania which covers an area of $945000 \mathrm{~km}^{2}$, has a current estimated population of about twenty-nine million, a population density of about thirty persons per $\mathrm{km}^{2}$, a population growth of $2.8 \%$ per year and a largely rural population $(85 \%)$. The economy suffers from low investment, low production, agricultural dependency, a small tax base, unfavourable terms of trade, high debt and until recently wasteful and excessive bureaucratic coordination. It is only in the last few years that the private sector has been acknowledged as an important sector in the economy.

Despite several home grown and International Monetary Fund-World Bank brokered structural adjustment programmes, Tanzania's economy declined from an annual per capita GNP of more than US\$ 300 in the 1960 s and 1970 s to an estimated US\$ 100 in the early 1990s, categorizing Tanzania among the three least-developed countries in the world. However, during the last couple of years, the overall GNP rose from a negative growth in the early 1980 s, reaching $1.4 \%$ in 1985 when the Economic Recovery Programme was instituted, to $4 \cdot 1 \%$ in 1989 where it seems to have stabilized since then. Recently, the World Bank has depicted Tanzania along with Ghana and Zimbabwe as examples of successes of structural adjustment policies in Africa, but at the same time criticized donors for not honouring their support pledges in time. While the 1960-70s witnessed equitable economic growth, the post-adjustment years saw an unprecedented inequitable economic growth which if not addressed by the political reforms remains a serious threat to the social economic development of the poor.

Politically, Tanzania has been one of the 'stable islands' in Africa. Democraticallyelected civilian governments have been in power since independence in 1961, with a peaceful transfer of power from the first President, Mwalimu Nyerere to the current 
President Alli Hassan Mwinyi in 1985. There has been a strong political commitment to improvement in health and nutrition since independence, with disease, ignorance and poverty declared to be the three major enemies. This commitment was reinforced by the 1967 Arusha Declaration on 'Ujamaa' and it was given practical effect in 1973 when the then ruling party, Tanganyika African National Union, and its successor in 1977, the Chama Cha Mapinduzi, adopted an ambitious policy of providing free of charge all social basic services for health, education and public water supplies, with emphasis on rural areas. This was backed up by massive government financial, organizational and human resource development, and allocation to these services resulted in an impressive health, education and water infrastructure and for some time smooth delivery of the service virtually free for all. However, for a number of reasons, including economic mismanagement, unfavourable terms of trade and a decline in economic investment, the resource base to sustain the user-free services has been severely eroded, leading to their severe decline in quality. Thus, the structural adjustment policies of the mid-1980s saw as their first cut in public expenditure, cuts in the social services, reducing resource allocation to nutrition-relevant actions. Unless each of the emerging political parties puts children first on the political agenda and continues to be embarrassed by the high rates of mortality and morbidity, including undernutrition, there is also a threat of a decline in political commitment.

\section{A framework for investing in nutrition}

The nutrition field does not belong to a particular sector. Nutrition status is an outcome of various social processes in society. While commercial investments must be in an environment conducive to investment for economic returns it must also carefully choose the area of investment both in terms of the products and geographical location. Likewise in the area of nutrition we need to ask ourselves two major questions. The first is why invest in nutrition? The second is what constitutes an investment in nutrition and in which areas must we invest to maximize impact? In answering this question we need to have consensus on what constitutes the problem and causes of malnutrition. When we are agreed on this then it will be easier to agree on what actions should be taken to ameliorate the situation. These actions will then constitute the areas for our investment in nutrition. An important contribution by Tanzania in this area of consensus building for nutrition investment was the development of a unified conceptual framework which helps to identify priority areas for investment.

Although Tanzania had been spared many of the natural calamities and civil strife which befell many of its neighbours, it became clear towards the end of the 1970s that malnutrition in young children was very serious. This was in spite of political commitment and the efforts of the Government, non-governmental organizations (NGO) and external agencies to improve basic education, health services, and agricultural production. This prompted the Tanzania Food and Nutrition Centre (TFNC), which had been established as a semi-autonomous body by an act of Parliament in 1973 under the Ministry of Health, to initiate a process to review and re-formulate strategies and policies related to nutrition. It was obvious that continuing with the same policies would have no impact on nutrition. The result was a Food and Nutrition Policy drafted in 1980. Based on two decades of experience in nutrition intervention since independence, a systematic inquiry into the causes of malnutrition revealed that malnutrition was not just another 


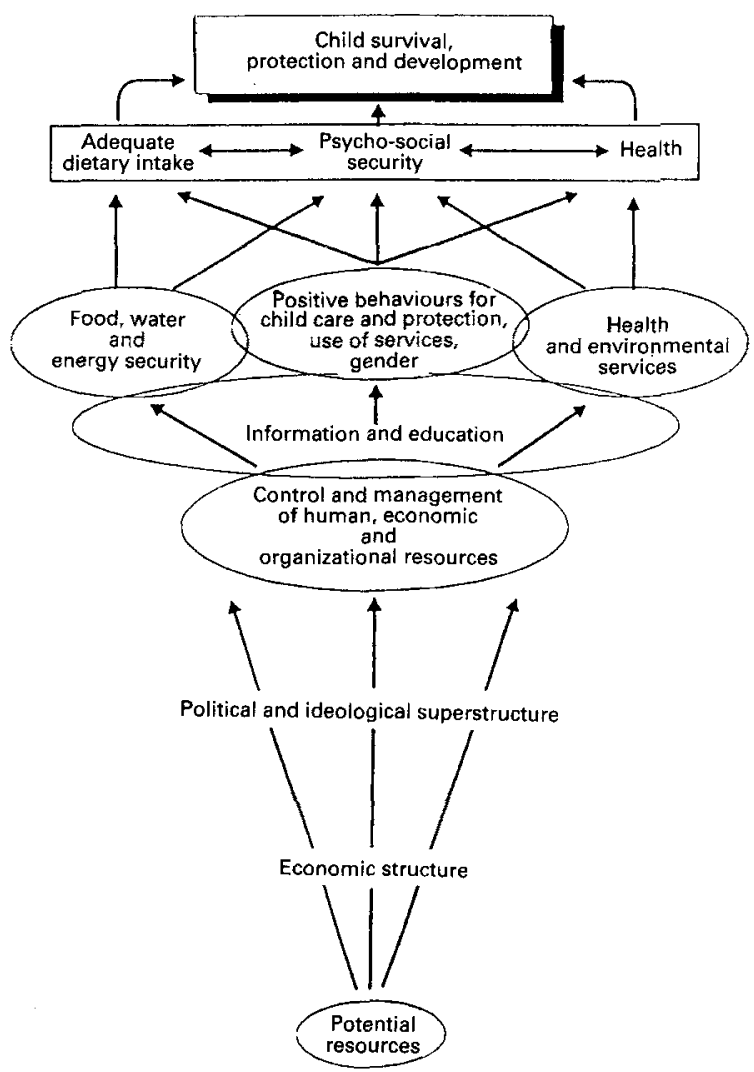

Fig. 1. Conceptual framework for analysis, used in the development of the nutrition strategy approach to addressing malnutrition.

disease, but a biological manifestation of deeper social problems in society with immediate, underlying and basic causes. Thus, addressing malnutrition is both a scientific and an ethical imperative. The inquiry also revealed that in addressing the situation, the poor should not be seen as passive beneficiaries of commodities and services, but as active participants. They are not the problem, but part of the solution to the problem.

A grant from the Joint World Health Organization (WHO)/UNICEF Nutrition Support Programme (JNSP) in 1983 provided the opportunity to try out the emerging strategy and policy in the Iringa region. The community-based Iringa Nutrition Programme (1983-1988) resulted in substantial declines in malnutrition, and soon became a model for addressing problems of malnutrition in children and women in Tanzania. The lessons learnt expanded not only within Tanzania but also provided inspiration and ideas for similar efforts to many other parts of the world.

The conceptual framework for addressing malnutrition which emerged from the pilot Iringa JNSP has been refined over the years to produce the 'nutrition strategy' approach, with TFNC, Urban Jonsson and Bjorn Ljungqvist as the principal authors. The nutrition strategy has now been adopted by various countries and agencies and can be used as a general development strategy as well. It is composed of a conceptual framework (Fig. 1) and a 'triple $A$ ' cyclic process of assessment, analysis and action (Fig. 2). 


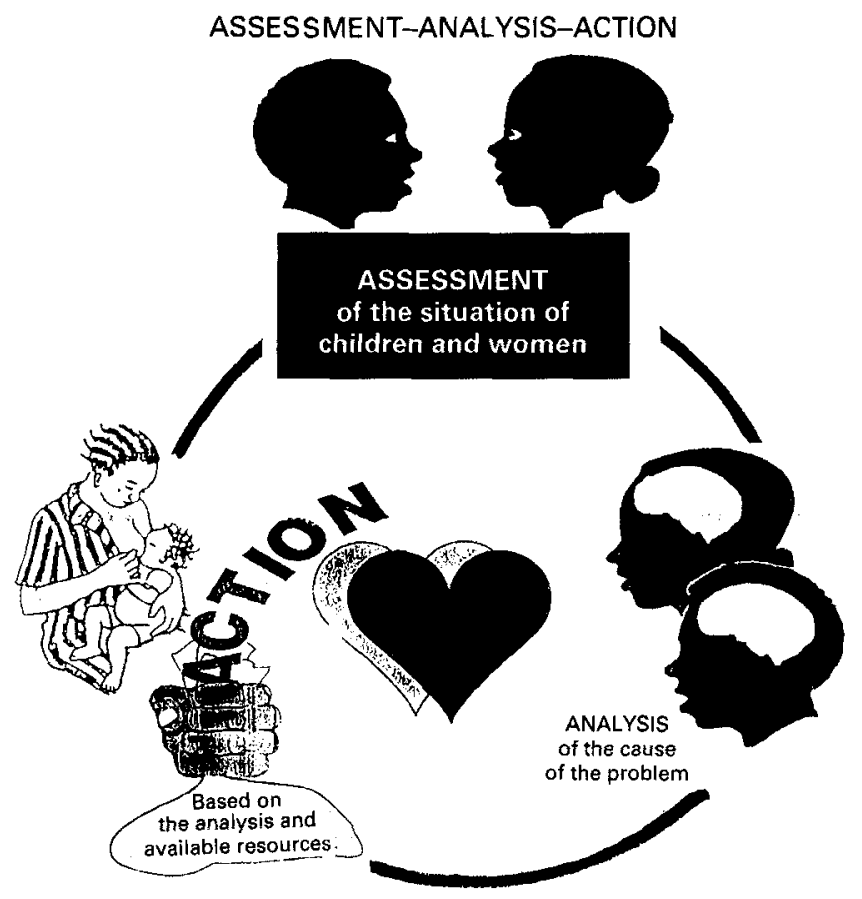

Fig. 2. 'Triple A' cyclic process of assessment, analysis and action, used in the development of the nutrition strategy approach to addressing malnutrition.

The conceptual framework with its implicit gender analysis is useful in reflecting the many dimensions of the malnutrition problem and it encourages shared understanding of both the ethical and scientific positions which it encompasses. The 'triple A' cycle creates a good basis for adaptive programming, essential in dynamic situations as it leads to the re-design of programmes as it cycles. In addition, it indicates where resources should be re-allocated for maximum quality and impact. Its ability to deal with successive rapid approximations of the situation avoids delays in taking action and focuses better assessment, analysis and action as it cycles. The process generates and uses nutrition information at community level in order to improve the capacity of households, village governments and local authorities to assess and analyse their problems more accurately, enabling them to use their own resources more effectively. Recognizing the existence of 'triple A' cycles at all levels facilitates 'adaptive coping' processes and, therefore, is not an imposition. External resources facilitate mobilization of internal resources by strengthening and focusing existing 'triple A' cycles toward nutrition improvement. The strategy seeks as its ultimate aim the creation of behaviour conducive to nutrition improvement to the national level by each individual from the household. It puts the communities in control of their own situation; an essential ingredient of programme ownership. People are prepared to take risks in issues they feel are theirs. The best development programme is that about which, after it is completed, people would say 'we did it ourselves'; for people cannot be developed, but can be supported to develop themselves. 


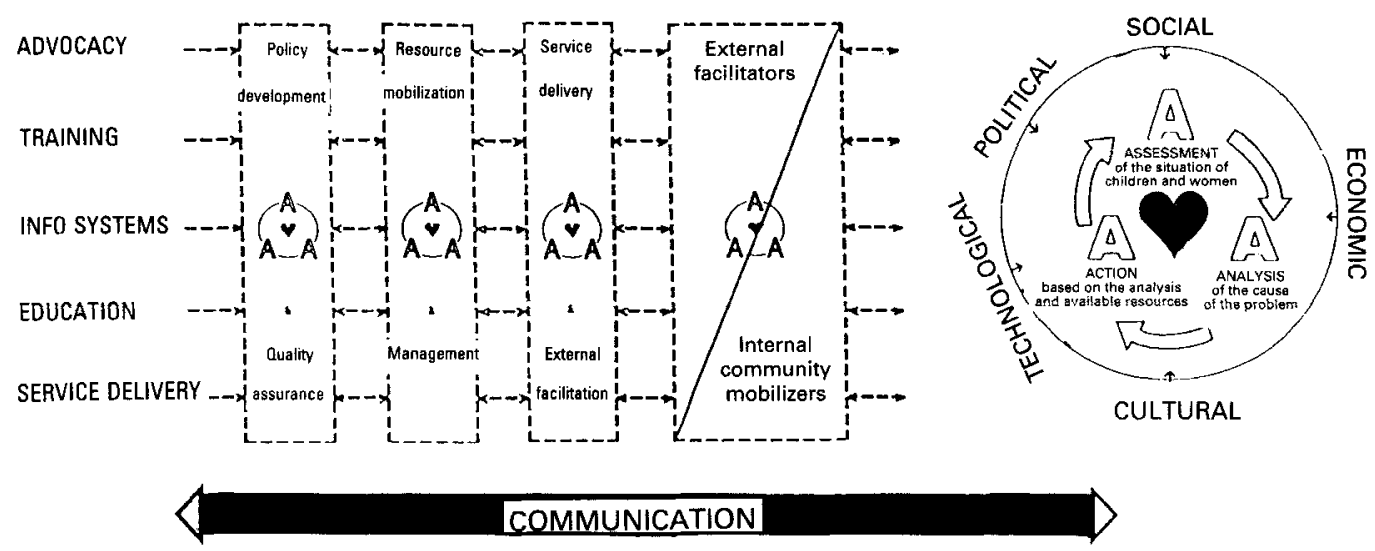

Fig. 3. Conceptual framework for social action developed to bring the nutrition strategy approach to malnutrition into operation.

As a response to the challenge of bringing the nutrition strategy into operation, a conceptual framework for social action has been developed, as shown in Fig. 3. The Executive Board of UNICEF adopted the nutrition strategy in 1990 and it now forms the basis for UNICEF's programming in nutrition (UNICEF, 1990).

\section{Financial investments in nutrition}

While government spending on services relevant to nutrition (agriculture, education, health, housing, community development, social welfare, water and environmental sanitation and other social services) rose sharply in Tanzania during the 1970s, reaching about $50 \%$ (agriculture receiving 30\% of government spending) it fell sharply during the economic crisis, and especially during the structural adjustment years of the 1980s, declining to as low as $5.6 \%$ for agriculture in the period 1986-91. As shown in Table 1 , contrary to common belief that in Tanzania resource allocation to social services has been better than in the neighbouring countries, the truth is that with the exception of health where it has been just about the average, resource allocation to these services has been below average. Botswana, Mauritius and Zimbabwe, admittedly relatively-smallpopulation countries, did very well in expanding all levels of education and health services. Tanzania excelled in resource allocation to administration, a reflection of the bureaucratic coordination of the social and economic systems of the two decades after independence. However, the political and structural reforms of the late 1980s brought down the allocation to administration by slightly more than $10 \%$, from the high $34 \%$ of 1985-7 period to an average of about $21 \%$ during the 1987-91 period (Kavishe \& Mushi, 1993). Further reductions which could be allocated to nutrition are possible. Allocation for both education and health further declined during the years of Economic Recovery Programmes, stabilizing at about 6 and 5.0\% respectively during the 1987-91 period without much recovery in recent years. The question which arises is how nutrition improved at a time of dwindling government resource allocation to nutrition-relevant sectors?

Three explanations have been advanced. First, while government expenditure in social 
Table 1. Percentage allocation of central government expenditure by main sectors in selected countries in Eastern and Southern Africa region (1980-2 - 1985-7)

(From UNICEF, 1992)

\begin{tabular}{|c|c|c|c|c|c|c|c|c|}
\hline \multirow[b]{2}{*}{ Country } & \multicolumn{2}{|c|}{ Education } & \multicolumn{2}{|c|}{ Health } & \multicolumn{2}{|c|}{ Defence } & \multicolumn{2}{|c|}{ Administration } \\
\hline & $1980-2$ & $1985-7$ & $1980-2$ & $1985-7$ & $1980-2$ & $1985-7$ & $1980-2$ & $1985-7$ \\
\hline Botswana & $20 \cdot 3$ & $18 \cdot 1$ & $5 \cdot 7$ & $6 \cdot 1$ & $8 \cdot 3$ & 8.8 & $19 \cdot 4$ & $16 \cdot 8$ \\
\hline Ethiopia & $9 \cdot 8$ & $10 \cdot 0$ & $3 \cdot 5$ & $3 \cdot 3$ & $?$ & $?$ & $41 \cdot 2$ & $28 \cdot 2$ \\
\hline Kenya & $20 \cdot 0$ & $21 \cdot 5$ & $7 \cdot 7$ & $6 \cdot 4$ & $13 \cdot 5$ & $9 \cdot 0$ & $10 \cdot 0$ & $10 \cdot 6$ \\
\hline Lesotho & $13 \cdot 1$ & $15 \cdot 5$ & 4.9 & $6 \cdot 9$ & $?$ & $?$ & $?$ & $?$ \\
\hline Madagascar & $14 \cdot 6$ & $16 \cdot 7$ & $4 \cdot 0$ & $5 \cdot 7$ & $?$ & $?$ & $22 \cdot 6$ & $29 \cdot 8$ \\
\hline Malawi & $11 \cdot 5$ & $10 \cdot 7$ & $5 \cdot 3$ & $6 \cdot 4$ & $9 \cdot 6$ & $5 \cdot 8$ & $14 \cdot 9$ & $17 \cdot 1$ \\
\hline Mauritius & $16 \cdot 0$ & $13 \cdot 5$ & 7.2 & 7.7 & $1 \cdot 3$ & 0.8 & $17 \cdot 2$ & $13 \cdot 2$ \\
\hline Rwanda & $18 \cdot 5$ & $15 \cdot 7$ & 3.7 & $3 \cdot 2$ & 11.4 & $8 \cdot 8$ & $16 \cdot 1$ & $13 \cdot 4$ \\
\hline Swaziland & $21 \cdot 2$ & $21 \cdot 5$ & 6.6 & $8 \cdot 1$ & $7 \cdot 0$ & $5 \cdot 5$ & $20 \cdot 3$ & $20 \cdot 9$ \\
\hline Tanzania & $13 \cdot 0$ & $8 \cdot 3$ & 5.8 & $5 \cdot 7$ & $10 \cdot 7$ & $15 \cdot 8$ & $23 \cdot 0$ & $34 \cdot 0$ \\
\hline Uganda & $13 \cdot 3$ & 13.9 & $5 \cdot 1$ & 2.9 & $24 \cdot 3$ & $21 \cdot 0$ & $26 \cdot 3$ & $22 \cdot 6$ \\
\hline Zambia & $12 \cdot 8$ & $10 \cdot 3$ & $6 \cdot 8$ & $5 \cdot 3$ & $?$ & $?$ & $40 \cdot 8$ & 31.9 \\
\hline Zimbabwe & $19 \cdot 1$ & $21 \cdot 4$ & $6 \cdot 3$ & $6 \cdot 7$ & $21 \cdot 0$ & $16 \cdot 4$ & $15 \cdot 0$ & $11 \cdot 3$ \\
\hline Average & $15 \cdot 6$ & $15 \cdot 2$ & $5 \cdot 6$ & $5 \cdot 7$ & $11 \cdot 9$ & $10 \cdot 2$ & $22 \cdot 0$ & $20 \cdot 8$ \\
\hline
\end{tabular}

services declined, households and communities had to increase their allocation because they were charged by the service providers or because free services were not available or were too poor in quality. There is evidence to indicate that some communities make contributions in cash and in kind to the community-based programmes through a variety of ways pertinent to their situations. Some communities have provided additional feeding to the severely malnourished; in others child minders, village health workers or water-pump technicians are paid a monthly stipend by communities through the village governments; others have built schools, health posts, public latrines or provided their labour in other self-help schemes. Second, the liberalization and adjustment policies of the late 1980s increased private, donor and NGO involvement in the delivery of services. The third explanation is that the use of the nutrition strategy focused resources for greater impact.

Recently, TFNC (Ndossi, 1994) did an analysis of resource flows and programmed actions for the achievement of the International Conference on Nutrition (ICN; US Agency for International Development, 1992) goals in Tanzania. This was done under the auspices of the United Nations Administration and Coordination Committee/ Subcommittee on Nutrition, as a preliminary survey to evaluate the adequacy of resource flows into direct nutrition projects in three countries (the others are Kenya and Zimbabwe). The results show that for Tanzania the resources allocated or committed by the government, bilateral, multilateral, and donor agencies are too small to achieve the ICN nutrition goals. Furthermore, the allocations for 1992-4 show a declining trend. For 1994-5 about US $\$ 5 \cdot 3$ million have been allocated by both the government and donors, which translates to about US $\$ 0.9$ per child per year against an estimated need of US $\$ 8.0$ million or US $\$ 1.3$ per child per year. Even this estimate is a gross underestimate as the annual per capita cost of the successful JNSP and child survival, protection and development (CSPD) programmes show that about US $\$ 3.0$ per child per year is needed 
to achieve a measurable impact. The World Bank estimates even higher costs for the provision of an essential package of care in low-income countries in Africa which is about US\$ 13 per capita per year (World Bank, 1993). This package has three major components: health care and facilities, institutional support, and incremental interventions. Direct nutrition intervention is one of the sub-components of incremental interventions and is costed at US\$ 1.32 per capita per year, which is the same as Ndossi's (1994) estimate of US\$1.3 per child per year for Tanzania. This is a clear indication that there does not seem to be an increased allocation to improve nutrition by both donors and the government as required by both the World Summit for Children and the ICN. The fact that the declines in the incidence of underweight have continued indicates that households and communities are not imitating this bad trend.

\section{Human resource investments in nutrition}

An important component of nutrition programmes in the 1980s was the development of human capacity through both formal and in-service training. Tanzania has more than 10000 village health workers; and another 10000 extension staff in agriculture, health and education. Most of these have been trained to focus their services toward the improvement of nutrition through seminars, workshops, study tours or in their formal training by reviewing their curricula. In addition, strategic district, regional and national officials, including policy makers, have received orientation in nutrition and have proved to be excellent strategic allies.

\section{Organizational investments in nutrition}

Tanzania has elaborate institutions which support various aspects of development and nutrition programmes from the national to the grassroots level. Although some of the structures were party structures during the one-party era, many have been retained as government structures after the shift to multi-party democracy. The system is highly decentralized, although there are many officials with centralist behaviour.

Extensive community-level formal and informal structures make it possible to identify by name any child, woman or household at risk of nutritional problems through the ten cell system where approximately ten households are organized under an elected leader. In addition there are approximately 9000 villages with their own village government, more than 200 wards, 365 divisions, 106 districts and twenty regions and, of course, the national ministries which are supportive to grassroots initiatives. All the sub-national administrative structures have by law a multi-sectoral Health Committee where nutrition matters are discussed. The health infrastructure is widespread and there is a primary school in every village. Moreover, there are a number of popular non-governmental institutions and bilateral and multilateral agencies and donors who support nutritionrelevant actions.

The highly decentralized nature of the structures described previously and strong political commitment have been crucial to the success of the child survival, protection and development programmes. The creation of the TFNC, which has been the technical force behind the programmes, is one of the government's most cost-effective organizational investments in nutrition. The centre, which harmonizes nutrition-relevant interventions in Tanzania, has been particularly successful in facilitating multi-sectoral 
collaboration, catalysing initiation of relevant programmes and providing the necessary technical back up for the programmes. It has also been the force behind the development of workable strategies, has significantly contributed to the development of ideas and has inspired both the national and international nutrition community.

\section{MAXIMIZING QUALITY AND IMPACT: \\ PROGRAMMATIC CONTEXT AND COSTS}

The JNSP and CSPD programmes provided the programmatic basis for the operationalization of the nutrition strategy. The major thrust was not the introduction of a pre-packed technical package, but of a method or an approach which strengthens and focuses existing 'triple A' cycles. This was in recognition of the fact that the main actors at the community level in improving nutrition, i.e. the parents, community leaders, extension staff and other resource people are already assessing, analysing and trying to cope with an ever-changing environment. Weighing of children by village-based extension staff provided the assessment tool on which analysis and design of actions were based. By 1993, more than 2.0 million children (about $50 \%$ of children under 5 years) were registered in the CSPD programmes in the whole Zanzibar JNSP and in twelve of the twenty regions of the Tanzania mainland (UNICEF, 1993). The average cost per year is about US\$ 3 per child, down from the initial costs of US\$ 19 per child in the Iringa JNSP. In expanding the programme, efforts were made to define the most important components crucial to programme success and how these core elements could be implemented in a sustainable and cost-effective manner. These core elements include advocacy and communication, integrated training, community-based information systems, service delivery and targeted education to help in the analysis. Observations indicate that most programmes in Africa exclude the beneficiaries from serious analysis, which is a crucial element in improving the quality of programmes. These core elements constitute the social-action package for nutrition improvement which, as shown in Fig. 3, is a package for accelerating the 'triple $A$ ' cycles. Promoting and supporting this package in Tanzania, including the Iringa region, currently costs between US\$ 2 and 4 per child per year, a most modest cost indeed.

The outcome of the programmes has been very striking. Impressive reductions in rates of undernutrition, child deaths and common childhood diseases have been recorded, with spectacular increases in immunization. The reductions in malnutrition have been more pronounced for the severe forms (Fig. 4) than for total malnutrition (Fig. 5) and most reductions occurred during the first 18-24 months of the programme. The challenge now is to further reduce these levels and replicate the process nationally to achieve the 1990-2000 decade goals for nutrition. This, of course, requires sustained financial, organizational and human resource investments in large-scale community-based nutrition-relevant activities by donors, the government, households and the communities themselves.

\section{CONCLUSION}

Several lessons can be learnt from the Tanzanian experience in investing in nutrition. The first is that investing in community-based interventions is a most cost-beneficial approach. All higher levels should be supportive through both a bottom-up and 


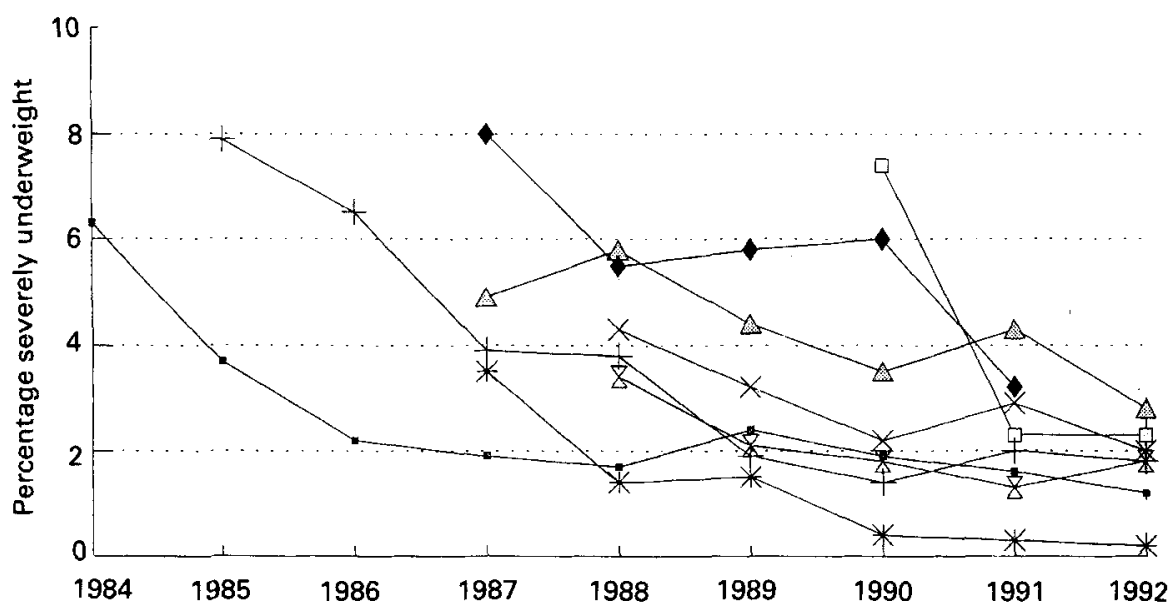

Fig. 4. Trends in severe underweight within the child survival, protection and development programmes in eight areas of Tanzania in 1984-1992. ( $\mathbf{0})$, Iringa; (+), Kagera; (*), Kilimanjaro; $(\square)$, Mara; (×), Morogoro; $(\diamond)$, Mtwara; ( $\Delta)$, Ruvuma; $(x)$, Shinyanga. (Data derived from Tanzania Food and Nutrition Centre and United Nations International Children's Emergency Fund nutrition database (UNICEF, 1992).)

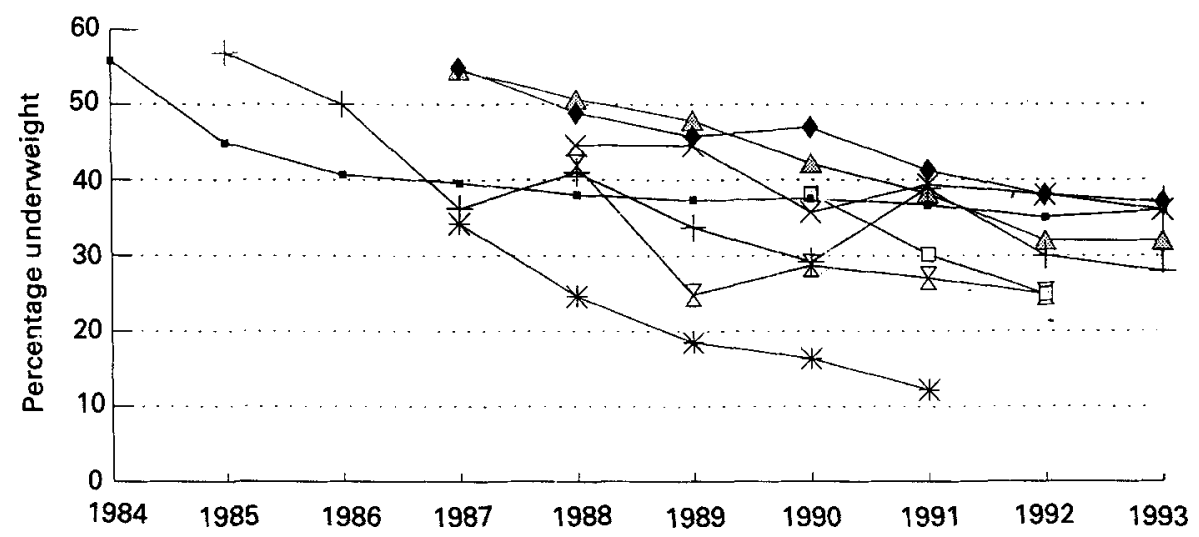

Fig. 5. Trends in total underweight within the child survival, protection and development programmes in eight regions of Tanzania in 1984-1992. (ש), Iringa; (+), Kagera; $(*)$, Kilimanjaro; $(\square)$, Mara; $(x)$, Morogoro; $(\diamond)$, Mtwara; (A), Ruvuma; ( $\times$ ), Shinyanga. (Data derived from Tanzania Food and Nutrition Centre and United Nations International Children's Emergency Fund nutrition database (UNICEF, 1992).)

top-down approach. Second, to achieve quality, impact and sustainability in a costeffective manner, investing in the social-action package comprising: advocacy and communication, community-based information systems, targeted and gender-sensitive education, training and service delivery, is good value for money. Promoting the package ensures that simultaneous actions are taken to address issues related to service delivery, capacity building and empowerment and builds up a sense of programme ownership. It is also an effective way of mobilizing financial, organizational and human resources for nutrition improvement. The process acknowledges an initial period of capacity building 
which may not give measurable results, as an essential component of the programme. This has the potential to conflict with the requirement of many donors who in most cases demand quantifiable impact only a short period after the programme has started. The monitoring of nutrition status in the 'triple A' cycle satisfied both aspects in the Tanzanian programme. However, it is essential for those involved in development programmes to appreciate that while it is important to set targets for measuring achievement and for monitoring progress, any significant development process has a time-lag between action and impact. As opposed to closed systems, actions aimed at influencing open systems like nutrition, population, family planning, the environment etc., have to be sustained over sufficient time to result in measurable impact. Since most development programmes address open systems, the logic, therefore, is to monitor the process before impact.

A crucial factor in implementing the nutrition social-action package, and development in general, is the management and leadership ability of those involved in such programmes. Although a number of people were trained in the application of the programme experiences, the major problem is that they are still too few and are, therefore, constantly being overworked. The ability to use the adaptive-process approach to programming in the design, implementation and management of programmes is an essential factor in programme quality and impact. Good programmes do not just spring up by the implantation of a model observed to be successful elsewhere. They require a visionary cadre of initiators able to conceptualize, adapt and adopt, mobilize, act and react and manage programmes in dynamic situations.

The problem of nutrition programme managers has in fact only been recently internationally acknowledged. It received much support when Alan Berg, a senior nutrition adviser at the World Bank, suggested in a much-publicized Martin Foreman Memorial lecture in 1991, that there is a need to develop a cadre of 'nutrition engineers' who are able to translate into practice available knowledge on addressing nutrition problems (Berg, 1991, 1993; Csete, 1993; Jonsson, 1993b). The type of person who is able to put together the 'nuts and bolts' of the various components of nutrition programmes, who will integrate science with ethics, knowledge with practice, draw lessons from experience and translate lessons into action. The lack of such managers has always been obvious to those of us involved in nutrition programmes in the field. It is a surprise that it has taken so long to reach the ears of the international nutrition community. It points to an area where investment could make a great contribution to improving nutrition.

\section{REFERENCES}

Berg, A. (1991). Sliding Toward Nutrition Malpractice: Time to Reconsider and Redeploy. Martin Forman Memorial Lecture. Presented at the Annual General Meeting of the National Center for International Health, Washington, DC, 24 June, 1991. Washington, DC: National Center for International Health.

Berg, A. (1993). Malnutrition and 'nutrition engineering' in low income countries: A rejoinder. International Journal of Health Services 23, 615-619.

Csete, J. (1993). Malnutrition and 'nutrition engineering' in low income countries: A comment on Alan Berg's vision of the nutrition track record. International Journal of Health Services 23, 607-614.

Davidson, B. (1992). The Black Man's Burden. Africa and the Curse of the Nation-State. Washington, DC: Times Books.

Dumont, R. (1962). False Start in Africa. New York: Andre Deutsch.

Jonsson, U. (1988). A Conceptual Approach to Understanding and Explanation of Hunger and Malnutrition in Society. Hunger and Society. Cornell International Monograph series no. 17. 
Jonsson, U. (1993a). Nutrition and the United Nations Convention on the Rights of the Child. Innocenti Occasional Papers. Child Rights Series no, 5, New York: UN.

Jonsson, U. (1993b). The global embarrassment of malnutrition and the role of nutrition engineers. Letter to the editor. International Journal of Health Services 23, 579-580.

Kavishe, F. P. \& Mushi, S. S. (1993). Nutrition-relevant Actions in Tanzania. TFNC Monograph Series no. 1. UN ACC/SCN Country Study Supported by UNICEF. A Case Study for the XV Congress of the International Union of Nutritional Sciences, September 26 to October 1, 1993, Adelaide.

Ndossi, G. (1994). Resource Flows and Programmatic Actions for the Achievement of ICN Goals in Tanzania. TFNC Report no. 1632, May, 1994.

UNICEF (1990). UNICEF's Nutrition Strategy. New York: UNICEF.

UNICEF (1992). Africa's Recovery in the 1990s. From Stagnation and Adjustment to Human Development [G. A. Cornia, R. van der Houven and T. Mkandawire, editors]. Spedale degli Innocenti Florence, Italy: International Child Development Centre.

UNICEF (1993). We Will Never Go Back. Social Mobilization in the Child Survival and Development Programme in the United Republic of Tanzania. New York: UNICEF.

UNICEF (1994). The Progress of Nations, 1994. The Nations of the World Ranked According to Their Achievements in Child Health, Nutrition, Education, Family Planning and Progress for Women. New York: UNICEF.

United Nations Administration and Coordination Committee/Subcommittee on Nutrition (1992). Second Report on the World Nutrition Situation, vol. 1, pp. 17-36. Geneva: ACC/SCN.

US Agency for International Development (1992). International Conference on Nutrition. World Declaration and Plan of Action for Nutrition. Rome, December 1992. Washington, DC: USAID.

World Bank (1989). Sub-Saharan Africa: From Crisis to Sustainable Growth. Washington, DC: World Bank.

World Bank (1993a). World Development Report 1993: Investing in Health. Oxford: Oxford University Press.

World Bank (1993b). A Framework and Indicative Cost Analysis for Better Health in Africa. Africa Technical Department, Human Resources and Poverty Division, Technical Working Paper no. 8. Washington, DC: World Bank. 